\title{
SEQUÍA VIEJA Y LOS BAÑADOS DE AÑATUYA EN SANTIAGO DEL ESTERO. NODO DE DESARROLLO LOCAL E INTERACCIÓN MACRORREGIONAL
}

\section{SEQUÍA VIEJA AND THE BAÑADOS DE AÑATUYA IN SANTIAGO DEL ESTERO. NODE OF LOCAL DEVELOPMENT AND MACROREGIONAL INTERACTION}

\author{
Constanza Taboada \\ E ISES (CONICET) - IAM (UNT) E-mail: constanzataboada@gmail.com
}

Presentado el: 05/11/2013 - Aceptado 23/05/2014

\begin{abstract}
Resumen
El artículo explora la posibilidad de conformación de una región prehispánica alrededor de los Bañados de Añatuya (río Salado medio, Santiago del Estero, Argentina) y el papel central que el sitio Sequía Vieja pudo desempeñar como nodo de relaciones, alianzas y encuentros entre poblaciones locales, andinas y del Noreste Argentino. Se plantea también la perduración e importancia de este nodo durante la Colonia. Para ello se describe y analiza material artefactual procedente de colecciones, enfatizando el estudio de indicadores de origen andino y chacolitoraleño (objetos de metal, cuentas de minerales de cobre y Spondylus?, pichcas, pipas, rasgos cerámicos, entre otros). La información se articula con resultados de trabajos de campo propios en el sitio Sequía Vieja y área vecina (caracterización, primeros fechados, estructura).
\end{abstract}

Palabras claves: Sequía Vieja - Santiago del Estero - inca - NEA

\begin{abstract}
This paper explores the possibility of a pre-hispanic region surrounding the Bañados de Añatuya (Middle Salado river, Santiago del Estero, Argentina) and the importance that the site of Sequia Vieja might have had as a node of relationships, aliances and communication with Andean and Chaco-littoral populations. Moreover, it is proposed that this node not only endures over Colonial times, but also remains very important during this period. For that reason, we describe and analyze the archaeological collections recovered in the site, emphasizing the study of indicators of Andean
\end{abstract}


and Chaco-littoral origins (metal objects, beads made of copper mineral and Spondylus, pichcas, pipes, pottery, among others). This study is combined with the results of the fieldwork carried out by our team in the site and the area (characterization, first datings, structure).

Keywords: Sequía Vieja - Santiago del Estero - inca - NEA

\section{Introducción}

En el centro sud de Santiago del Estero (departamento Avellaneda), sobre la margen oeste del curso medio del río Salado, se ubica Sequía Vieja, un sitio tardío/colonial muy particular. Hasta ahora no había sido descripto en la bibliografía ni estudiado de forma sistemática, lo que comenzamos a hacer desde 2012. La mayor parte de lo que se conoce de él procede de excavaciones realizadas en la década de1940 por Asbjörn Pedersen (1951) y Emilio Wagner (Wagner y Righetti 1946). Estos investigadores aportaron gran cantidad de materiales que nos interpelan por su carácter alóctono en la zona (sobresale el registro de varias decenas de objetos incaicos de metal -Angiorama y Taboada 2008-) y que requieren ser puestos en perspectiva histórica ya que carecen de datos contextuales. Esta situación, sumada a que la zona fue objeto de asentamiento y desarrollo de diferentes procesos prehispánicos y coloniales, introduce un importante factor de complejidad a la hora de evaluar las acciones que los involucraron. Sin embargo, una perspectiva que enfoca a la trama de situaciones y resoluciones que los pueblos de la región debieron enfrentar en su interacción con demás grupos, y a las coyunturas que implicaron el avance y caída inca, la conquista hispana y el avance de grupos del este, empieza a abrir intersticios para explorar la situación material que presenta el sitio y el área.

La significación del sitio y del área reside en la confluencia de gran cantidad de objetos indígenas ajenos al registro regional, propios de tradiciones andinas e incaicas (además de objetos incaicos de metal asociados a investidura y denotación de poder, cuentas de minerales de cobre y de Spondylus?, pichcas, rasgos cerámicos) y del Noreste Argentino (pipas sobre todo). Este tipo de bienes se ha encontrado en abundancia en el sitio Sequía Vieja y en menor medida y variedad en algunos pocos más de sus vecinos inmediatos, pero no en el resto de los cerca de 200 sitios conocidos para Santiago. Sequía Vieja se destaca de sus vecinos del área, además, por su mayor densidad de ocupación y tamaño (15 hectáreas). Todos los sitios que registran los bienes señalados se ubican en un sector bien definido -tanto natural como histórica y arqueológicamente- de unos $30 \mathrm{~km}$ de largo enclavado en las lomas altas de los Bañados de Añatuya (Figura 1), en plena zona de habla quichua y de sobreinstalación de pueblos de indios coloniales.

Los bienes mencionados proceden de colecciones y requieren ser puestos en perspectiva histórico-temporal, contextual-funcional y simbólico-social para poder avanzar en el conocimiento de las identidades y dinámicas de las poblaciones que los poseyeron y circularon. Sin embargo, si consideramos que sus trayectorias de incorporación, uso y descarte debieron seguir diferentes cursos y abarcar tiempos y pasos distintos en que se mantuvieron vigentes, la situación comienza a cobrar sentido. En otros trabajos hemos analizado cómo pudieron haber llegado o sido apropiados y producidos por procesos diferenciados según el caso (regalos, incorporación de prácticas sociales, reformulación de rasgos estilísticos, retorno de agentes) (Taboada y Angiorama 2010, Taboada et al. 2013). Varios datos nos llevan a pensar también que algunos de ellos se mantuvieron en circulación en momentos postcontacto o que 

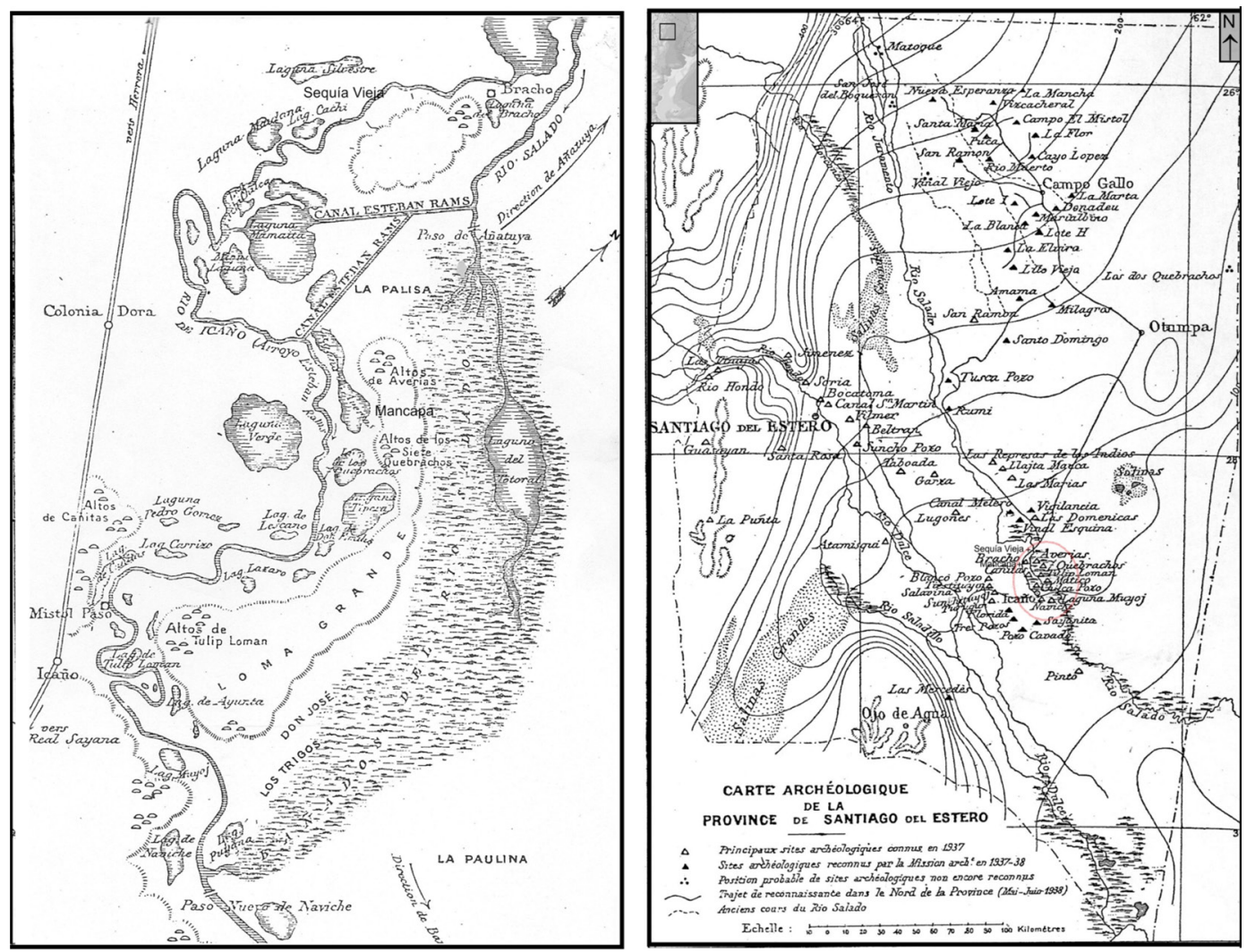

Figura 1. Mapas del área de estudio modificados de Reichlen (1940) con la inclusión de los sitios de Sequía Vieja y Mancapa en ubicación aproximada.

finalizaron en contextos funerarios; trayectorias y significaciones que irán siendo develadas a medida que avancemos en la identificación de contextos y en la exploración de modelos sobre la vida de estas poblaciones.

En función de revertir esta situación, primero reubicamos el sitio Sequía Vieja (Taboada y Angiorama 2005) y desde 2007 analizamos parte de los materiales del área (Angiorama y Taboada 2008, Taboada y Angiorama 2010, Taboada 2011, Taboada et al. 2013). A partir de la presencia de piezas de metal de diseño y factura incaica y valliserrana tardía propusimos que las mismas podían estar reflejando contactos con los incas, y que esta interacción parecía desenvolverse específicamente en torno a las poblaciones de esta zona acotada del Salado en donde se concentran o aparecen con exclusividad los materiales que referimos arriba. En base a otros indicadores, donde retomamos hipótesis planteadas inicialmente por Lorandi $(1980,1984)$, pensamos mecanismos diferenciados de circulación de los objetos e ideas en relación a distintas situaciones de interacción generadas en tiempos prehispánicos tardíos y principios de la Colonia con poblaciones de los valles intervenidas por el incario donde aparecen objetos muy similares -como La Paya, valle de Lerma y Potrero de Chaquiago(Taboada y Angiorama 2010, Taboada et al. 2013). Paralelamente exploramos potenciales vínculos con las poblaciones del este del Salado y empezamos a señalar diversidad material y en los procesos sociopolíticos de momentos prehispánicos tardíos y coloniales (Taboada 
2011, 2013a, Farberman y Taboada 2012). La generación de información sistemática de campo recién pudo concretarse a partir de 2011 en el área y de 2012 en el sitio (Taboada 2013a, b). Si bien estos trabajos no han revelado aún material del tipo del señalado, están brindando elementos importantes para reducir el grado de irresolución cronológico-contextual y para avanzar en la comprensión del funcionamiento del sitio y de las poblaciones que lo habitaron y usaron dichos objetos. Con base a ello, en este artículo planteamos que la zona alrededor de la cual se distribuyen estos sitios y materiales pudo constituir una región o territorio con desarrollos particulares respecto del resto de la llanura santiagueña, donde Sequía Vieja pudo tener un papel sociopolítico destacado que le permitió actuar como cohesionador y foco de encuentro y articulación de redes locales, regionales e interregionales en tiempos pre y postcontacto hispano.

Para ello asumimos una perspectiva que concibe a la materialidad arqueológica como referente de prácticas de la vida cotidiana y social manifestadas en usos y consumo de objetos, rasgos y habilidades y en su contextualización en el espacio social de producción y circulación (Bourdieu 1988, Lemonnier 1992, etc.). Buscamos así explorar las relaciones, marcaciones y procesos sociopolíticos sobrevenidos al interior de las poblaciones estudiadas. Partimos para ello de la formulación de un modelo dinámico sobre la vida de las poblaciones de la región, que se orientó a repensar las prácticas indígenas y la relación entablada con otros grupos a partir de una mirada que puso en juego información histórica y etnográfica (Taboada 2013a). El modelo discute la homogenización al interior de la llanura santiagueña; la fronterización entre poblaciones de tierras altas y bajas y los estereotipos que las ubican en dos polos de complejidad, así como una relación conflictiva constante con los grupos del chaco y litoral. Concibe, además, la continuidad reelaborada de estructuras, estrategias y mecanismos indígenas durante la Colonia negociando o actuando por fuera del control español en el desarrollo de prácticas cotidianas y en la significación y circulación de objetos.

\section{El sitio Sequía Vieja: características, cronología y organización territorial}

En el paraje denominado Acequia Vieja se registra un área con evidencias arqueológicas fijada en la bibliografía con el nombre de yacimiento de Sequía Vieja, pero del que no contamos con descripciones previas, salvo una muy breve de Amalia Gramajo (1991). Según nuestras prospecciones y primeras excavaciones, las mismas se distribuyen con diferente grado de densidad y características (tipo de evidencias, cronología) en una superficie de unas 15 hectáreas que parecen dar cuenta de diferentes eventos de uso y ocupación.

El sitio se emplaza en un área de monte chaqueño, con abundantes arbustos espinosos que hacen intransitables ciertos sectores y condicionan fuertemente la visibilidad. La zona se ubica a unos $3 \mathrm{~km}$ al oeste del cauce actual del río Salado. El sitio se reconoce por la presencia de cuantioso material cerámico en superficie y por la sucesión de gran cantidad de formaciones monticulares de tierra y áreas elevadas de diferente tamaño, forma y altura afectadas y recortadas por procesos naturales y antrópicos. Hay una gran cantidad de alfarería pintada Averías, aunque también están representadas otras manifestaciones cerámicas hasta ahora no discriminadas en la bibliografía. En superficie se hallan también torteros en una alta proporción y, de hecho, de las colecciones del sitio proceden cerca de 4000. Ocasionalmente se recupera algún fragmento u objeto de metal, aunque hasta ahora no hemos hallado ninguno de tipo incaico como los encontrados por Pedersen y Wagner. A diferencia de otros sitios del área, como Mancapa, donde también estamos trabajando, no es común el hallazgo de restos óseos humanos y la exposición de bocas de vasijas o parte 
de ellas en perfiles o a ras del suelo. Creemos que esto se debe a cuestiones de formación de sitio y sectorización funcional y cronológica. El análisis bibliográfico, las prospecciones, la distribución del material en superficie y la excavación de 15 cuadrículas en cuatro montículos ubicados en tres sectores distintos del sitio, más una primera datación obtenida, nos permiten sostener que el sitio fue ocupado desde época prehispánica tardía hasta colonial, y que dichas ocupaciones parecen haberse desarrollado en sectores parcial o totalmente distintos. La presencia y características de material europeo colonial (que luego detallaremos) sumados a datos históricos permiten plantear que el asentamiento se configuró luego en uno de los pueblos de indios coloniales más importantes del área (Taboada y Farberman 2013).

El primer fechado radiocarbónicos obtenido para el sitio ubica a un contexto doméstico sin evidencia de material postcontacto (sector del sitio denominado en adelante SV19), con una probabilidad de 0,984 de ubicarse entre 1426 y 1497A.D. (Tabla 1). O sea, claramente prehispánico y parcialmente contemporáneo con el período incaico en el NOA, lo cual es coherente con los materiales de dicho origen hallados. en el sitio Las dataciones obtenidas en Mancapa, un sitio vecino con materiales similares a los de Sequía Vieja, permiten sostener que el asentamiento en el área es anterior y perduró en la Colonia, lo que es avalado por información histórica (Taboada y Farberman 2013).

\begin{tabular}{|l|l|l|l|l|l|}
\hline $\begin{array}{c}\text { Sitio, } \\
\text { estructura o sector } \\
\text { y unidad de } \\
\text { procedencia }\end{array}$ & Material & $\begin{array}{c}\text { Código de } \\
\text { laboratorio } \\
\text { (Latyr) }\end{array}$ & $\begin{array}{c}\text { Edad } \\
\text { radiocarbónica } \\
\text { convencional }\end{array}$ & $\begin{array}{c}\text { Rango de } \\
\text { 1o Cal A.D. }\end{array}$ & $\begin{array}{c}\text { Área } \\
\text { relativa }\end{array}$ \\
\hline $\begin{array}{l}\text { Mancapa 1- } \\
\text { UP 103 }\end{array}$ & Carbón & LP-2759 & $790 \pm 50$ años AP & $1226-1290$ & 1 \\
\hline $\begin{array}{l}\text { Mancapa 3- } \\
\text { UP 302/R1 }\end{array}$ & Carbón & LP-2776 & $550 \pm 60$ años AP & $1394-1451$ & 1 \\
\hline $\begin{array}{l}\text { Sequía Vieja 19- } \\
\text { UP 106C2 }\end{array}$ & Carbón & LP-2819 & $470 \pm 50$ años AP & $\begin{array}{l}1426-1497 \\
1603-16061\end{array}$ & 0,98431 \\
\hline $\begin{array}{l}\text { Mancapa 2- } \\
\text { UP 204 }\end{array}$ & Carbón & LP-2766 & $310 \pm 40$ años AP & $\begin{array}{l}1510-1575 \\
1621-1654\end{array}$ & 0,593206 \\
\hline
\end{tabular}

Tabla 1. Fechados radiocarbónicos de Sequía Vieja y Mancapa. Factores de Corrección: ${ }^{12} \mathrm{C} /{ }^{13} \mathrm{C}$ (estimado): $-24 \pm 2 \%$. Factor multiplicador del error $(\mathrm{K})=1$. Calibración para el Hemisferio Sur: SHCal04 14c Mc Cormac et al. 2004.

Sequía Vieja se destaca además por su dimensión, densidad y complejidad interna con relación a los otros sitios de la zona. Los trabajos de campo, fechados y el estudio de las colecciones y bibliografía sobre el área nos muestran que alrededor se distribuye un conjunto de sitios menos destacados parcialmente contemporáneos y con similares evidencias alóctonas, aunque mucho más escasas en cantidad y variedad. Ellos son Mancapa, Siete Quebrachos, Tulip Loman, Chilca Pozo, Laguna Muyoj, Cañitas, Icaño, Real Sayana y quizás algunos más. El sitio Averías, en cambio, parece poder ocupar otro lugar preeminente dentro del conjunto, al compartir con Sequía Vieja la magnitud de objetos ajenos al registro local, pero también con ciertas diferencias que permiten especular algún tipo de distinción no aclarada aún. El área de instalación de estos sitios es más alta que el terreno circundante, inserta a su vez en una zona de bañados, antiguas lagunas y paleocauces (Fig. 1), donde el río Salado pierde su lecho encajonado para recuperarlo justo donde se cortan los sitios con evidencias semejantes: 
"Hasta Figueroa, el Juramento [Salado] corre hoy en un lecho bien encajonado a causa del declive bastante rápido del terreno, pero a partir de ese punto, el suelo se vuelve tan plano que las aguas, a la menor crecida, salen de su lecho para formar innumerables lagunas o esteros, volviendo imposible la navegación sobre ese río. Sobre el mapa arqueológico de los alrededores de Icaño [Fig. 1], he reconstituido la topografía de la región comprendida entre el Bracho y Naviche [exactamente la zona en la que se ubican los sitios arqueológicos con características materiales similares] en una época (1910) en que las crecientes del río se producían aún regularmente y he podido indicar, gracias a las informaciones provistas por el Sr. Emilio R. Wagner, junto a los bañados del Río Salado, 35 lagunas grandes o pequeñas. A partir de Naviche, se encuentra un lecho bien demarcado, que va a encontrarse con el Río Paraná, cerca de Colastiné" (Reichlen 1940: 138, trad. A. T. Martínez).

Si bien la descripción de Reichlen abarca un área un poco más extensa a la que nosotros delimitamos, ya que incluye también los Bañados de Figueroa ubicados más al norte, se aprecia igualmente que el área que nos ocupa constituye una unidad ambiental definida desde el punto de vista de su geodinámica y recursos. La configuración y actividad es claramente diferente a la del sector aguas arriba y abajo, tanto por su accesibilidad a un río no encajonado como por la dispersión cuando sale de madre. La zona conforma un ambiente muy particular y diverso en cuanto a posibilidades para la caza, pesca, recolección, siembra, instalación humana, movilidad y defensa, que le confieren una unidad no sólo ambiental sino también cultural en lo que respecta al modo de apropiación y uso (Lorandi y Lovera 1972, Taboada 2013a). En este sentido, tanto desde el punto de vista del ambiente, uso del espacio, homogeneidad material interna y procesos históricos y sociopolíticos a los que parece remitir, el área se muestra como muy coherente y nos hace pensar en una región o territorio particular. Como contraparte cabe señalar que los sitios arqueológicos conocidos ubicados aguas arriba y debajo de esta zona parecen diferentes, tanto por la ausencia de los objetos señalados como ajenos a la tradición local, como por las características distintas de los materiales locales -en relación a variantes cerámicas sobre todo- y por la ausencia de evidencia colonial (Wagner y Wagner 1934, Bleiler 1948, Reichlen 1940, Lorandi 1978, Taboada y Farberman 2013).

\section{Los materiales de Sequía Vieja en perspectiva cronológica, histórica y cultural}

\section{Metales, caracoles, piedras y tejidos: regalos, intercambios, intereses, estrategias}

De Sequía Vieja se han publicado 60 objetos de metal (sobre un total de 112 registrados en 9 sitios del área y de 140 publicados para todo Santiago-Figura 2-. Hay algunos más registrados directamente en el Museo de Ciencias Antropológicas y Naturales "Emilio y Duncan Wagner" de Santiago del Estero -en adelante MW-). De esos 60 objetos, al menos 40 son de época prehispánica tardía o incaica y 13 no presentan elementos para ubicarlos con precisión pero también podrían serlo (Angiorama y Taboada 2008). Similar proporción se mantiene para el total de los objetos del área. Hay también algunos coloniales sobre lo que luego volveremos (cruces, cascabeles y topus). Sumando los registrados en el MW, los de Sequía Vieja constituyen la mitad de los objetos de metal conocidos para Santiago; el resto procede mayoritariamente de Averías y en menor medida de los demás sitios de la zona salvo unas poquísimas excepciones. De los 60 objetos de Sequía Vieja publicados, 47 pueden ser considerados bienes de lujo (sensu Appadurai 1996) y vincularse a representación o atuendo personal (22 placas, 4 topus, 2 liwi, 3 toki, 2 hachas planas, 1 hacha ancla, 1 pendiente, 2 mazas estrelladas, 2 manoplas o tensores, 1 campana, 7 campanillas,) y 11 son utilitarios (cinceles, punzones). A ellos se suman 2 lauraques procedentes del sitio no contabilizados 
anteriormente. Esta vinculación de la mayor parte de los objetos a vestimenta e investidura andina resulta muy sugerente, en tanto la indumentaria y la portación de ciertos objetos eran indicativas de identidad étnica o status del individuo y estaba reservada a personajes de la elite y del sistema de gobierno incaico (Decoster 2005). Por su parte, así como varios de los elementos se vinculan a tocados y emblemas portados por los hombres en el mundo

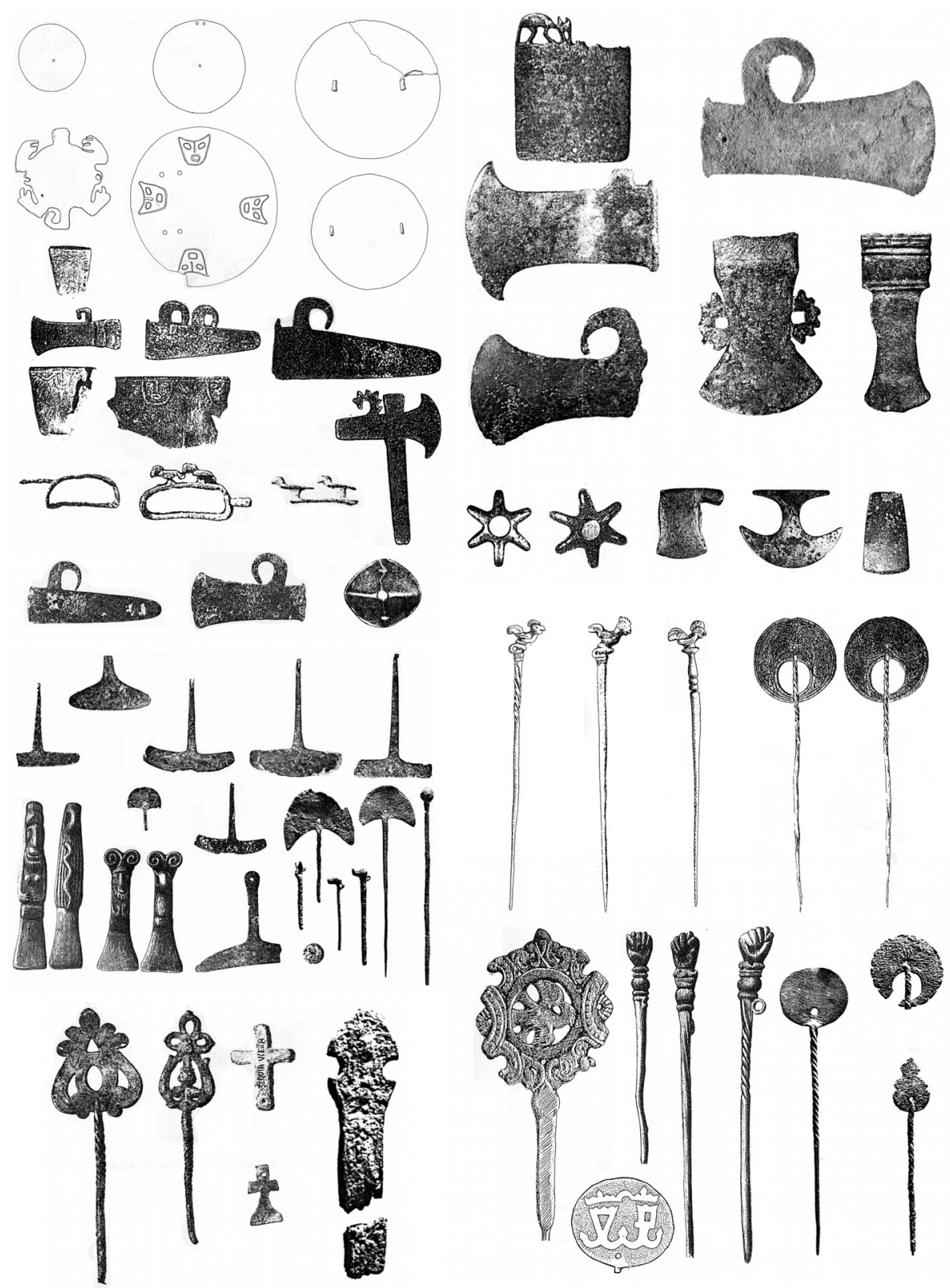

Figura 2. Algunos de los objetos de metal recuperados en la zona de los Bañados de Añatuya (ilustrado en Taboada y Angiorama 2010).Las figuras han sido tomadas de Reichlen 1940, Wagner y Righetti 1946, Pedersen 1952, Gramajo 1979, Mayer 1986 y González 1992. Los objetos no han sido ilustrados a una única escala porque las piezas no cuentan con esa información en las publicaciones. 
andino, un número significativo de objetos y rasgos remiten al género femenino y su potencial relevancia en el proceso analizado (en particular lauraques y topus, multiplicidad de torteros y actividad textil).

De Sequía Vieja se conservan cerca de 4000 torteros y varias centenas más de los sitios del área. Si bien muchos de ellos podrían remitir a obrajes textiles funcionando dentro de los pueblos de indios coloniales del área -algunos sobreimplantados sobre asentamientos prehispánicos-, pensamos que la tradición se remontaría a momentos prehispánicos y esta destreza y/o materias primas como el algodón podrían haber sido motivo de interés y aún de intervención incaica (Taboada y Angiorama 2010, López Campeny 2013). Torteros hallados en excavaciones sistemáticas en contextos tardíos de Santiago datados o sin evidencia colonial (Lorandi 1978) y en el sondeo fechado en Sequía Vieja (SV19) apuntalarían su preexistencia en la región, así como la asociación a contextos coloniales su perduración. Torteros similares del sitio incaico Potrero de Chaquiago y otros casi idénticos -aunque de madera- encontrados en contextos incaicos de La Paya y el Valle de Lerma junto a elementos de tradición de la llanura santiagueña como cerámica Averías/Yokavil, que Lorandi (1980, 1984) interpretara como producto de mitimaes del llano traslados a los valles, refuerzan el planteo (Taboada et al. 2013). Dentro de la misma perspectiva, los objetos de metal podrían haber jugado como dones para entablar y sostener alianzas entre el incario y ciertas poblaciones del río Salado (Angiorama y Taboada 2008, Taboada y Angiorama 2010). Este intercambio pudo haberse constituido tanto a partir de una primera oferta de vasallaje por parte de poblaciones de la llanura (Lorandi 1980, Castro 2013, Taboada et al. 2013) como también haber sido buscado y/o mantenido por el incario mediante el juego de reciprocidades con jefes locales y en donde los objetos de metal pudieron actuar -junto a algunos otros elementos - como bienes propicios para su consolidación, incorporándose quizás luego a la vida social local y siguiendo trayectorias diversas.

En consonancia, algunos otros elementos alóctonos hallados en Santiago pueden ser vinculados a prácticas incaicas privativas de ciertos grupos sociales o circunstancias de negociación con poblaciones locales, tales como caracoles y cuentas minerales y el juego de la pichca. Los Wagner (1934) señalan haber recuperado caracoles del Pacífico, y nosotros hemos identificado entre los materiales del MW un objeto pseudocircular con orificio central -o "cuenta" - de color rojo anaranjado con vetas blancas, que según observación macroscópica parece corresponder a Spondylus, el caracol sagrado de los incas de las costas del Pacífico. A ello se agrega que, procedentes de Sequía Vieja, hay también buena cantidad y variedad de "cuentas" discoidales y tubulares de minerales azules y verdes (que parecen ser lapislázuli, malaquita o similares), materias primas ajenas a la región y usadas por los incas y poblaciones locales del NOA bajo su influjo en collares y adornos de personajes distinguidos y ajuares fúnebres (Bárcena 2001, Cremonte y Gheggi 2012, Oliveto y Ventura 2009, entre otros).

\section{Un juego ritual andino}

A lo expuesto se suma un objeto muy particular que identificamos en las colecciones de Sequía Vieja del MW. Se trata de una pirámide cuadrilátera trunca de cerámica de 40 $\mathrm{mm}$ de alto y $38 \mathrm{~mm}$ de base, con círculos grabados en sus caras en cantidades de 1, 2, 3 y 4 y que podría remitir al juego incaico de la pichca, dispersado por la región surandina con la conquista incaica (Gentile 1998, Castro Rojas y Uribe 2004) (Figura 3). Muestra gran similitud con los ejemplos publicados por estos autores en cuanto a forma, tamaño y marcas 
diferenciadas (círculos, líneas, cruces) en cinco de sus caras y Gentile ha vinculado con dicho juego otros dos objetos procedentes de Santiago, justamente de la zona que analizamos. Uno procede del sitio Averías y es un pirámide trunca casi cubica pintada según patrón Epiaverías, estilo que según veremos es típico del área acotada que nos ocupa y se asocia a vasos keriformes. El otro se halló en Laguna Muyoj -también entre los sitios de interés- y es una pirámide trunca con rayas y cruces grabadas (Gentile 1998). La pichca o huayru fue un juego ritual andino propio de las elites, usado en el establecimiento de pactos y reciprocidades y en la legitimación simbólica de las relaciones políticas entre el inca (o sus funcionarios) y las poblaciones locales (Gentile 1998, Castro Rojas y Uribe 2004).Un tipo de objeto que luego fue incorporado a la cotidianeidad de las poblaciones locales ya los rituales funerarios (Gentile 1998, Castro Rojas y Uribe 2004), y usado también como oráculo para la lluvia (Salomon 2002); algo más que útil -si fuera el caso- para las poblaciones de los bañados santiagueños, donde el mayor problema y el organizador de la vida son las inundaciones y sequías (Taboada 2013a

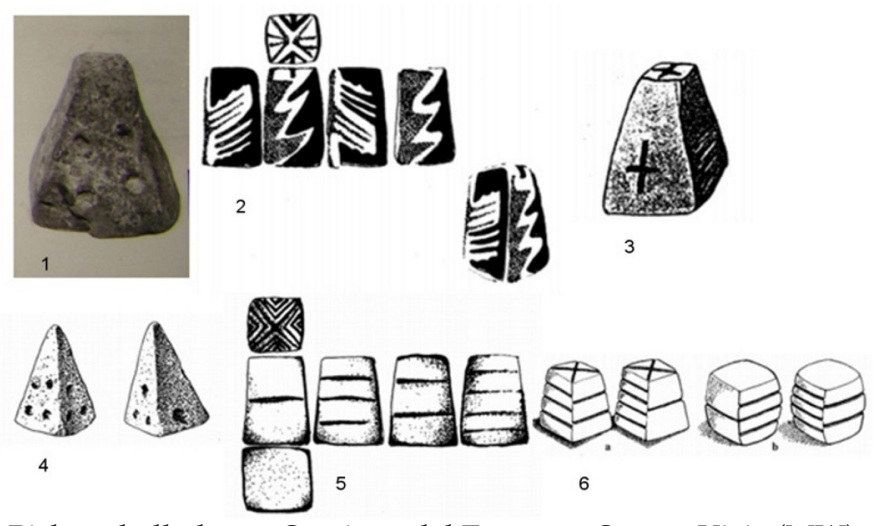

Figura 3. 1, 2 y 3 Pichcas halladas en Santiago del Estero en Sequía Vieja (MW), Averías y Laguna Mujoj respectivamente (Gentile 1998). 4, 5 y 6 Pichcas procedentes de Viluco (Mendoza), Pachacamac y Huaca Tres Palos en Perú respectivamente (Gentile 1998).

\section{Formas y estilos cerámicos locales: ¿representación diferenciada y comensalidad?}

Por su parte cabe señalar que en Sequía Vieja, Averías y algunos de los sitios de la zona inmediata los recipientes desarrollan formas distintas a las tradicionales de la llanura santiagueña, así como motivos de representación diferentes a los estilos tardíos definidos para la misma. Algunas de estas nuevas morfologías de piezas recuerdan a formas incaicas, como los vasos altos -con el registro incluso de un vaso doble- y los platos con apéndices zoomorfos que podrían remitir a platos patos (Gramajo 1982, Taboada y Angiorama 2010). Ambos se asocian a un estilo de representación aparentemente exclusivo de nuestra área de estudio, denominado Epiaverías -el de la pichca de Averías- (Bleiler 1948, Taboada y Angiorama 2010). Otros motivos presentes en recipientes del sitio, como cuatriparticiones, triángulos, rombos, zigzag y escalonados son frecuentes en aríbalos, jarras, vasos altos y platos incaicos Cusco Polícromo, además de aparecer en pucos Yokavil hallados en los valles asociados a elementos incaicos (Leiton 2010, Taboada et al. 2013).

Paralelamente, es interesante la situación que presentan otros recipientes del sitio. Si bien se mantienen tipos y elementos de la tradición tardía más general y conocida de la región, como el estilo Averías y las vasijas globulares, en Sequía Vieja y en Averías, están 
presentes formas y rasgos estilísticos que no habían sido identificados, aislados o reseñados hasta ahora. Se trata de grandes vasijas tricolor ahusadas y platos bicolor cuatripartitos (Fig. 4). Las vasijas ahusadas (en adelante vasijas Bracho Tricolor) son morfológicamente distintas a las clásicas vasijas globulares tardías de la llanura santiagueña. Esta forma está asociada, a su vez, a un nuevo diseño decorativo, que si bien mantiene los colores y algunos rasgos del tradicional Averías y Epiaverías, pierde la linealidad paralela e incorpora otros motivos, como círculos concéntricos, grecas, zigzags, reticulados y cuadrados con líneas interiores que resultan en un cambio esencial en su diseño final y podrían, además, remitir en algunos casos a pautas incaicas como las señaladas. Si bien todas las vasijas completas proceden de excavaciones sin datos de contextos, fragmentos de este tipo has sido hallados en nuestras excavaciones en asociación a contextos tanto coloniales como sin material colonial interpretados como prehispánicos (como es el caso de SV19).

Los platos son formas aparentemente ausentes en otras zonas. También presentan nuevos diseños, aunque distintos de los de las vasijas ahusadas. Un estilo presente casi exclusivamente en platos y vasos lo conforma el ya referido llamado Epiaverías. Pero aparte de este tipo de platos, aparece en el sitio otro tipo muy distinto, más plano, bicolor y con un manejo espacial del diseño también diferente (en adelante platos Sequía Vieja). Presentan fondo rojizo o ante cruzado en cuatripartición por líneas rectas simples, dobles o triples negras o marrones, o por bandas con zigzags internos en negativo (Figura 4). Fragmentos de estos platos fueron hallados en el sondeo de SV19 asignado a tiempos prehispánicos tardíos y también en contextos coloniales.

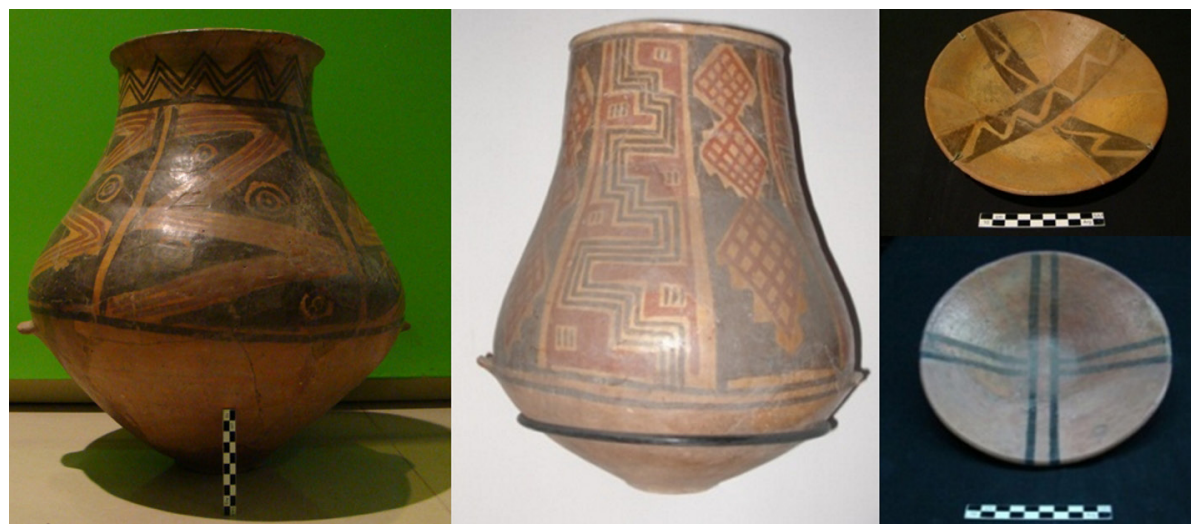

Figura 4. Vasijas ahusadas Bracho Tricolor y platos Sequía Vieja cuatripartitos procedentes de Sequía Vieja (MW).

Estas variantes de representación se restringen, a su vez, a tales formas y tamaños, los cuales podrían vincularse a contención de grandes cantidades de comida y bebida y a consumo comunitario según se ha estudiado para otros casos del NOA (por ej. Nielsen 2006). No podemos descartar tampoco el potencial uso como urnas funerarias de las vasijas ahusadas. Hasta el momento no hemos registrado estos diseños sobre otras formas clásicas del registro cerámico regional, ni tampoco sobre las formas incorporadas por el proceso colonial -que además son formas pequeñas vinculables a consumo individual-, lo que sí ocurre con el Averías más clásico y con Epiaverías. Estos tres tipos de recipientes (vasijas ahusadas, platos y vasos altos) que aparentemente aparecen en momentos inmediatos anteriores a la dominación española, emergen así "marcados" por nuevos o diferentes estilos. El hecho 
de que aparezcan como algo novedoso frente al registro de otros sectores de Santiago o al potencial registro anterior de la región, que sean quizás exclusivos del área y se presenten con sobreabundancia en Sequía Vieja, permite pensar en prácticas nuevas -tanto de consumo como funerarias-, vinculadas quizás a la necesidad de reconfigurarse y desarrollar estrategias identitarias para enfrentar situaciones de gran impacto como pudieron ser el avance incaico y la conquista española.

\section{Pipas y campanas: un río Salado permeable a la interacción}

Por su parte, también sin datos sobre su asociación contextual o cronológica entre sí ni con los objetos andinos ni locales, en Sequía Vieja y sitios cercanos se han hallado objetos y rasgos de tradición indígena del litoral y el chaco que permiten plantear interacciones con los pueblos de allende el Salado. Según se ha señalado, hacia el siglo XVIII, las poblaciones asentadas el este del Salado conformaban un territorio diferenciado e incursionaban y avanzaban hacia el oeste (Lucaioli 2008). Por esta razón, se dispusieron sobre la zona que nos ocupa una serie de fortines, constituyendo la llamada frontera del Salado. Sin embargo, la situación preexistente en relación a estos grupos -que habrá que discriminar- en la región es aún bastante desconocida y los elementos arqueológicos parecen indicar una situación menos conflictiva o aún de interacción hasta, por lo menos, los primeros momentos de la Colonia (Taboada 2011, 2013a, Taboada y Farberman 2013). La incorporación a diversos contextos de la llanura de alfarerías asignables a la entidad arqueológica Goya-Malabrigo (González 1977, Ceruti 2003, Politis y Bonomo 2012) con campanas donde los apéndices de psitácidos típicos del litoral han sido reemplazados por búhos (Serrano 1938) permite pensar en un contacto no eventual (Figura 5). Estos materiales aparecen en nuestra zona de interés, pero también en un área más extensa y con rango cronológico más amplio que apunta a interacciones también más tempranas (Lorandi 1978).
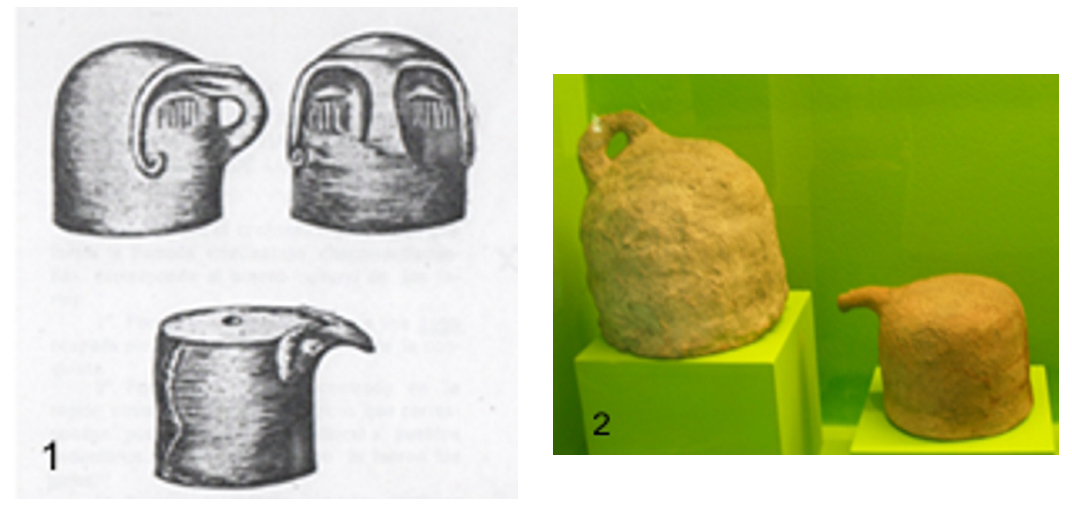

Figura 5. "Campanas" procedentes de Santiago del Estero. 1. Con representaciones de búhos (tomadas de Serrano 1938). 2. Sin representaciones (MW).

Con base a ello, resulta interesante señalar el hallazgo de cerca de 100 pipas de cerámica en Sequía Vieja y algunas más en Averías. Este registro, al igual que otros que referimos, es exclusivo del área acotada que nos ocupa. Análisis en curso apuntan a establecer fechados por AMS y sustancias fumadas. Aunque Reichlen (1940) las describe, fue Lorandi quien advirtió su carácter excepcional y la semejanza de algunas con pipas chaqueñas, señalando 
además la rara confluencia en el sitio con los objetos de metal (Lorandi 1978, ms). Hay de varios tipos, pero todas son pequeñas, cortas y muy pocas acodadas (Figura 6). Algunas presentan el hornillo hacia el centro del tubo, al estilo de las pipas monitor; en otras es evertido y ubicado en el extremo; en otras no sobresale del tubo. Pueden presentar decoración incisa geométrica o curvilínea. Pipas muy similares se han asignado a tradición indígena de la vera del Paraná -registradas también en la depresión del Salado y Río de La Plata (Bonomo 2013)- y a contextos coloniales como los de Santa Fe La Vieja (Carrara y De la Penna 2005, Letieri et al. S/F) donde hay registro de cerámica Averías que indica también interacciones establecidas con las poblaciones de la llanura durante la Colonia.

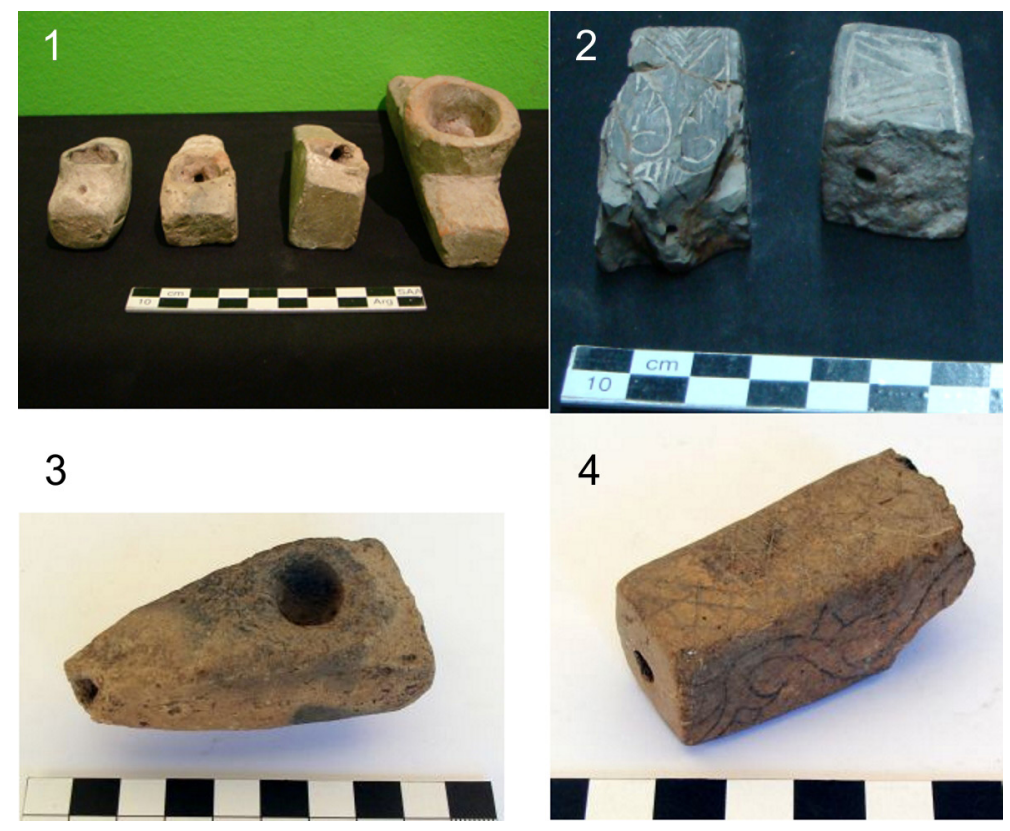

Figura 6. 1 y 2 Pipas procedentes de Sequía Vieja (MW). 3 y 4 Pipas de Santa Fe La Vieja (Letieri et al.S/F).

La incorporación de esta práctica en Sequía Vieja y alrededores, pero ausente en el registro del resto de la llanura santiagueña, nos plantea que en el sitio y área se desarrollaban e incorporaban entre últimos momentos prehispánicos y primeros coloniales, objetos y prácticas no sólo vinculadas a poblaciones andinas sino también del litoral, que se suman a las otras evidencias arqueológicas de la zona y a la documentación histórica que señala la alianza de poblaciones del área con grupos genéricamente llamados "chiriguanaes" para enfrentar a los españoles (Taboada y Farberman 2013). Tales situaciones nos llevan a pensar vínculos entablados con grupos del este en diferentes momentos y coyunturas y a seguir concibiendo al asentamiento que nos ocupa -y su organización y manejo interno- como potencialmente apto y funcional para el encuentro social y la negociación política a lo largo del tiempo. Cabe señalar, incluso, que en Sequía Vieja se han recuperado un par de pipas con decoración incisa geométrica similares a las que de Santa Fe han sido atribuidas a la población negra (Carrara y De La Penna 2005); otro aspecto a profundizar sobre las redes de conexiones, intercambios y presencia de distintos grupos étnicos en el sitio. 


\section{Volutas, jarritas y candeleros: la conformación de lo hispano indígena}

Como vimos, además de bienes de tradición prehispánica tardía, en Sequía Vieja se han hallado evidencias de factura hispano indígena y de origen o uso europeo, tales como fragmentos de loza Talavera, perlas venecianas, fragmentos de candeleros y sahumadores, cruces cristianas, hierro, ladrillos, huesos de animales introducidos, además de una tapa de pila bautismal. Gramajo (1991) recuperó en sondeos acotados en el sitio un fragmento de tortero en loza Talavera asociado a perlas venecianas y a cerámica indígena e hispano indígena en el nivel más superficial; nosotros también hemos comprobado en excavaciones la asociación contextual de material indígena, hispano indígena y europeo colonial en un espacio residencial. En este sentido, Sequía Vieja, y también Averías, se destacan por ser los sitios más representativos del Salado por su cantidad y variedad de material hispanoindígena y europeo colonial. Algunos de estos materiales son comunes en contextos coloniales del NOA, pero ciertos rasgos cerámicos parecen ser una manifestación más de las exclusivas del área. Nos referimos a una serie de motivos que hemos registrado por ahora sólo en esta zona de Santiago y podrían configurar un desarrollo estilístico particular en torno a los complejos procesos pericoloniales del área. Se trata de espirales, volutas, vírgulas y flores que se plasman sobre morfologías cerámicas distintas a las regionales y locales indígenas, sean europeas (candeleros, botellones, sahumadores) o no necesariamente (jarritas, vasos pequeños). Estas piezas fueron adscriptas por Gramajo (1979) a tradición hispano-indígena y algunos de los motivos a influencia árabe.

Sin embargo, nuestra observación nos acerca a otras posibilidades. Las volutas sobre las piezas hispano-indígenas que nos ocupan, y también los motivos en espirales en diversas ollas muy representadas en la zona inmediata al norte de nuestra área de interés (principalmente en los sitios Llajta Mauca y Las Represas de los Indios) asignadas a la fase Quimili Paso (Lorandi 1978) muestran mucha semejanza con la iconografía y cerámica chiriguana que reseñó Métraux (1929)(Figura 7), y podrían ser indicadores de movimientos y vínculos que poblaciones del chaco boliviano parecen haber establecido en momentos inmediatos previos al contacto europeo (Pärssinen y Siriänen 2003, Combès 2005, Oliveto y Ventura 2009). Ibarra Grasso (1981) ha señalado que los motivos de la cerámica chiriguana derivarían de la cerámica Mojocoya y de otras del sur de Bolivia. Lorandi (1978) señaló la similitud estilística entre estas y la cerámica Averías en función de pensar un contacto y avance de grupos de esa región como agentes de desarrollo de ese nuevo estilo cerámico en la llanura santiagueña, además de otras pautas andinas como el tejido. Resulta interesante notar que el diseño en espirales es uno de los más frecuentes en los torteros de Santiago y aparece también en los topus y lauraques. Hasta dónde pudo ser una vía de comunicación con los Andes, es por ahora una incógnita a seguir explorando (Lorandi, com. personal 2013). De hecho, estudios de casos en Bolivia y valles orientales de Salta permiten sostener interacción, producción y circulación de bienes -algunos representados en nuestra área de estudio en Santiago, como cuentas minerales, metalurgia andina, multiplicidad de torteros, etc.-, personas e ideas entre poblaciones locales e incas a través de la vertiente oriental de los Andes (Pärssinen y Siriänen 2003, Alconini 2004, Oliveto y Ventura 2009, Cruz y Jara 2011).

Sin embargo, volviendo a nuestro caso, quedan aún puntos a resolver. No existe por ahora una correspondencia cronológica ni espacial entre el momento y lugar más temprano detectado de aparición de la cerámica Averías y la incorporación de volutas en la cerámica asignada como hispano indígena. Por el contario, las volutas rompen con la tradición lineal recta y paralela de Averías. El momento más temprano en que Lorandi (1978) detecta ma- 

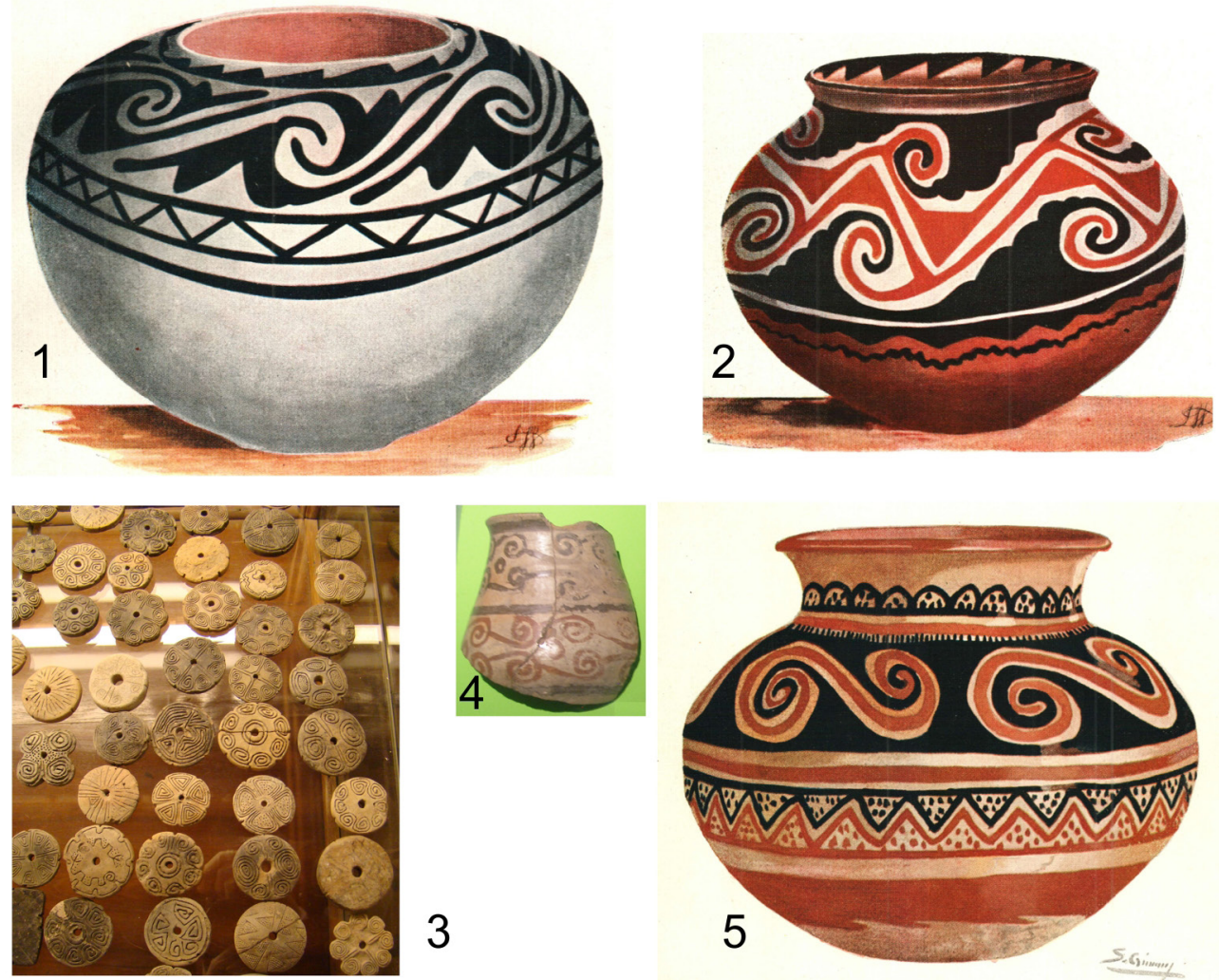

Fig.ura 7. 1 y 2 Ollas procedente de Las Represas de los Indios (Wagner y Wagner 1934). 3 Torteros con volutas y espirales (MW). 4 Fragmento de vaso con volutas considerado hispano-indígena de Sequía Vieja (MW). 5 Olla chiriguana (Métraux 1929).

terial Averías-aún escaso- fue definido como una fase diferenciada, la Fase Quimili Paso, aislada en un sitio de la mesopotamia santiagueña y ubicada entre 1200 y $1400 \mathrm{D}$. de C. (sin embargo, si hoy calibramos los fechados se alarga el rango hacia momentos un poco mas tardíos). Este material Averías no presentaba motivos en vírgulas ni espirales -pero sí las ollas con espirales asignadas a esa fase-. Tampoco se refieren dichos motivos en la fase posterior, Oloma Bajada Icaño (Lorandi 1978), que incorpora sitios de nuestra área de estudio; y nosotros tampoco los hemos registrado en las intensas prospecciones y excavaciones sistemáticas realizadas en Sequía Vieja -a pesar de hallarse en piezas de las colecciones del sitio y de Averías-. Esto nos lleva a la necesidad de interponer posteriores análisis que incluyan el material con espirales registrados al norte de nuestra área y atribuible precisamente a la fase Quimili Paso de Lorandi (1978) para determinar si la situación no se debe a variaciones espaciales e identitarias, como la propia Lorandi dejó planteado, y/o a procesos diacrónicos entre sí. Por ahora, especulamos que la incorporación de volutas a la cerámica asignada como hispano indígena podría vincularse a un proceso de interacción chaqueño quizás más tardío que el que Lorandi plantea pudo dar lugar al desarrollo de Averías. Un proceso pericolonial y quizás particularmente vinculado al espacio que nos ocupa, ya que no hemos encontrado estos motivos en materiales procedentes del resto de Santiago, ni específicamente en los contextos coloniales del Dulce. 
Cabe señalar, por su parte, que el diseño en volutas de la cerámica hispano indígena se despliega sólo en recipientes pequeños, como jarras y vasitos (y en objetos europeos como candeleros y botellones). Nunca sobre los platos, vasos altos y vasijas ahusadas señalados precedentemente ni sobre otro tipo de recipiente de gran tamaño. Son, a diferencia notable de los anteriores, tamaños y formas asociables a prácticas individuales de ingesta y vinculables a situaciones o momentos de mayor control social o directamente emparentados a prácticas europeas. Especularmente, los estilos de representación de las grandes vasijas ahusadas Bracho Tricolor y de los platos Sequía Vieja cuatripartitos -que están presentes durante la colonia según comprobamos por excavaciones sistemáticas- no aparecen en las formas hispánicas ni en los recipientes pequeños señalados. Esto permite hipotetizar con un manejo simbólico interpuesto entre estos dos conjuntos de bienes asignables a uso en situaciones sociales diferenciadas. En el mismo sentido de interpretación puede entenderse el hecho de que hasta el momento ningún material ni fragmento con volutas ha sido hallado por nosotros en las intensas prospecciones, recolecciones de superficie y excavaciones en Sequía Vieja -incluidos dos contextos de época colonial con material predominante indígena-, algo notable dada la cantidad de material cerámico que tapiza el mismo. Esta situación, junto a la referencia de Gramajo (1991) de que el sector colonial donde excava en Sequía Vieja tenía poco material en superficie, poca potencia y escasos hallazgos, apunta un dato más a favor de que el sitio presenta sectores diferenciados en cuanto a funcionalidad y cronología de ocupación, y que tanto este tipo de objetos, como los de metal incaicos o las pipas -nunca hallados hasta ahora en excavaciones sistemáticas-, podrían vincularse a contextos muy particulares o de ubicación muy especial no evidenciada en superficie así como a una circulación, distribución y uso restringidos. Esto también podría dar cuenta de la diferente representación de materiales europeos en los dos contextos residenciales coloniales que excavamos en dos sectores del sitio.

\section{Conclusiones}

El conjunto de especificidades compartidas sólo por los sitios del área de los Bañados de Añatuya, y su preeminencia en Sequía Vieja, nos llevaron a pensar en una región o territorio particular y a Sequía Vieja como un sitio relevante en el manejo de las relaciones de las poblaciones de ese espacio y con otras diferentes y externas a él. Las características conocidas hasta ahora, sumadas a la perspectiva interregional que enmarca el planteo, lo muestran capaz de haber jugado un rol apreciable a nivel político, tal vez como referente y organizador de relaciones a nivel interregional, con los incas y pueblos del chaco y litoral, así como también para enfrentar las intervenciones coloniales. Un rol que quizás se configuró o consolidó en tiempos incaicos, para mantenerse luego durante la Colonia con la reformulación de estrategias y mecanismos de reproducción social que hicieran frente a las nuevas circunstancias. En este sentido, la recepción de agentes, delegaciones o incluso la conformación de juntas y reuniones político sociales con el consecuente posterior mantenimiento de esos vínculos y la incorporación de rasgos y objetos a la vida social y funeraria puede dar buena cuenta de las características, excepcionalidad, diversidad, ajenidad y riqueza material que ofrece el sitio, así como de la representatividad sectorizada de materiales y características dentro de él. De hecho, el desarrollo de encuentros intergrupales para negociar, organizar acciones conjuntas, o reforzar vínculos, no son prácticas ajenas a ninguna de las poblaciones mencionadas, como tampoco a las poblaciones locales que en sus "juntas y borracheras" apuntaban, según la documentación, a tres objetivos (Farberman 2005): alianzas militares, reuniones fúnebres y ritos propiciatorios. Eran espacios sociales de alto valor cohesionador y estratégico para hacer frente a inclemencias naturales y sociales. 
Los incas desarrollaban estrategias diversas para incorporar a las comunidades locales a su sistema. Uno de sus principales mecanismos de legitimación fue el manejo de la producción y circulación de bienes suntuarios o especiales (Earle 1994). Otro fue la negociación, los regalos y los banquetes. Dillehay (2003), entre otros, ha analizado cómo el consumo festivo fue una forma explícita o implícita de control estatal sobre las poblaciones locales en donde se articulaban las creencias de los kurakas y señores locales que tenían obligaciones recíprocas de hospitalidad y generosidad, particularmente en lo que concierne a los productos alimenticios y la bebida. "Los banquetes servían para varios propósitos sociales y se establecían alianzas para la guerra, matrimonios, movilización de trabajo, creación de poder político y ventajas económicas, así como redistribución de riqueza" (Dillehay 2003: 358-359). Un hecho característico de los convites políticos fue "la incorporación de elementos exóticos apropiadamente seleccionados de un repertorio estatal establecido, constituido por un aparato destinado al banquete estatal y local en la elaboración de rituales sociales de hospitalidad que ya habían sido establecidos en sociedades andinas anteriores a los incas. Estos elementos jugarían allí, principalmente, como «productos de lujo» en el sentido definido por Appadurai (1996): signos «retóricos» dentro del dominio político de representación y acción. En este sentido, su valor proviene de su origen exótico y de su percepción como objetos impresionantes y costosos en el sentido de inalcanzables, salvo para algunos pocos" (Dillehay 2003:360). En esta perspectiva, la presencia en el área en estudio de gran cantidad de objetos que pudieron haber operado como regalos, otros que pudieron haber actuado invistiendo a jefes locales y sus mujeres, y otros como la pichca en tanto juego para establecer las relaciones reciprocas de poder, articula notablemente bien como parte de las prácticas político rituales de modelar y simbolizar pacíficamente las relaciones con los grupos locales. A ello se suma el desarrollo de ciertos tipos de recipientes aptos para desplegar la hospitalidad y el encuentro, claramente marcados, además, como estilísticamente diferentes a los del registro regional y de desarrollo hispano indígena.

Las relaciones políticas afianzadas por estas "juntas" aparecen también en cuanto al establecimiento de alianzas intergrupales y defensa regional durante el enfrentamiento contra españoles, según analizamos en otro trabajo (Taboada y Farberman 2013). Dicha investigación señala a las poblaciones del área alzándose contra los españoles con el apoyo de grupos chiriguanaes - que la arqueología encuentra como cercanos en la interacción-, al menos coyunturalmente. Muestra cómo, en "las ciénagas" del Salado, los indígenas de diferentes grupos, incluidos chaqueños, hicieron "juntas" para organizarse y ofrecer resistencia en los primeros momentos de contacto, lo que además de reafirmar la cohesión de estas poblaciones entre si y el planteo territorial para el área, nos remite a la perduración de un mecanismo de reproducción social prehispánico reformulado para nuevas situaciones, como fueron las famosas "juntas y borracheras" demonizadas por los españoles. Una situación a la que quizás podríamos remitir también las pipas halladas en el sitio. Resulta indispensable rescatar a estas alturas las descripciones de Paucke (1943) para los mocovíes reducidos a orillas del Paraná, hacia donde desagua el río Salado y en donde se han registrado hallazgos típicos de las tierras altas y comunes a los hallados en la llanura santiagueña (Bonomo et al. 2011). Paucke relata cómo las fiestas y juntas, con invitados ajenos al poblado y que acampan por tiempo prolongado en las inmediaciones del mismo, aparecen todavía en el siglo XVIII como aglutinantes y convocantes para mantener las relaciones de reciprocidad mediante regalos, invitaciones y convites políticos. Describe no solo la perduración de este tipo de encuentros en la postcolonia, sino también la capacidad, "mano" y organización necesaria para convocarlas y para mediar entre las delegaciones que se instalan en los alrededores del pueblo por varias semanas con su bagaje material. 
Volviendo así a los diferentes objetos que nos convocaron al principio, no podemos dejar de preguntarnos cuáles fueron los itinerarios que siguieron. No sólo cómo se hicieron presentes en estos sitios de la llanura, sino cómo fueron incorporados, significados, apropiados, circulados y finalizaron su trayectoria dentro de la vida de las poblaciones de la zona. Algunos datos apuntan a que podrían haber sido hallados, al menos metales y pipas, en contextos funerarios. Esto resulta interesante porque remitiría a nuevas o diferenciadas modalidades funerarias para esta zona (para la que Reichlen (1940) refiere entierros en urnas con ajuar a su lado, mientras los Wagner (1934) habían señalado la ausencia de ajuar en Santiago y Lorandi (ms) no lo registra para sitios de otras zonas y épocas) y que sería acorde con todo el contexto de emergencia de nuevas prácticas. Esto remarcaría, además, una valoración y significación por la cual el bien es incorporado a determinados entierros. Un contexto final que sería coherente con la interpretación que planteáramos de los objetos de investidura personal hallados en Santiago como regalos a líderes locales (y que la documentación muestra se mantuvieron durante la colonia como caciques dentro de la encomiendas -Castro 2013) para afianzar vínculos y finalmente pasar a acompañar la inhumación de estos u otros personajes. Hasta tanto contemos con contextos para estos objetos, no podemos descartar que la trayectoria de estos bienes pudo estar mediada además por su incorporación a la vida diaria y a la perduración de uso como marcadores significativos. Del Río (2010) ha señalado cómo las autoridades étnicas coloniales de un centro multiétnico de la frontera oriental del Tawantinsuyu en Bolivia atesoraban símbolos incaicos de autoridad y prestigio (como adornos y hachas de metal, tejidos cumbi y collares de turquesas) para reforzar su jerarquía colonial. Una práctica que se extendió entre los mallku a lo largo de los Andes y fue reconocida por indios y españoles (Cummins 1998 en Del Rio 2010). En ese sentido, cabe señalar la identificación que hace Gentile (2012) del legado de bienes prehispánicos (textiles, topus y vasos de plata relacionados con el ceremonial incaico) en los testamentos de indios de cierto rango social de la Gobernación del Tucumán de la zona del piedemonte catamarqueño y de Santiago. Decoster, por su parte, ha señalado cómo los objetos incaicos pasaron, en un momento dado, de ser referentes de identidad étnica a ser señaladores sociales a fin de "recalcar las estrategias usadas para expresar, controlar, ocultar o transformar la proyección de una identidad colectiva específica en contextos sociales contradictorios" (Decoster 2005: 163). Estrategias de este tipo también podrían leerse en la correspondencia entre nuevas formas y motivos de recipientes vinculables a comensalidad versus recipientes individuales con motivos hispano-indígenas de nuestra área. Más aún, la presencia de objetos claramente vinculados a vestimenta femenina incaica de cierto rango como topus y lauraques, como así también a la principal actividad de las mujeres escogidas del incario como es el hilado -y registrada en Santiago colonial en relación al mismo género mientras los hombres eran quienes tejían (Garavaglia 1986)- nos hace pensar además en el rol primordial que pudieron jugar las mujeres en esta situación, incluso en la posibilidad de alianzas matrimoniales o intercambio de mujeres (Taboada 2013a). Desde la antropología biológica se ha señalado también esta última posibilidad (Drube 2009). Y la leyenda referida por Corcuera (2005) que señala que fue una princesa inca quien enseñó a tejer en Santiago nos acerca a través de otro tipo de dato a tal posibilidad. Pensemos que según la perspectiva incaica, quizás sólo las mujeres dedicadas al hilado y las compañeras de los jefes locales podrían hacer uso de topus y lauraques, y tampoco serían de uso indiscriminado los emblemas metálicos masculinos o las cuentas de minerales y de Spondylus. El control que, en general, los incas hacían sobre el uso y circulación de este tipo de objetos dentro de sus políticas de relaciones, sumado a la cantidad de otras evidencias señaladas sobre la presencia e interacción de poblaciones de la llanura en sitios incaicos de los valles, nos lleva a pensar que la posibilidad de llegada y circulación de estos bienes tan representados -en cantidad y 
variedad- a esta región acotada de la llanura debió ser movilizada por un proceso vinculado al incario, dejando abierta la posibilidad de que luego pueda haberse mantenido o cobrado vida propia a través de diversos mecanismos, necesidades o estrategias posteriores.

De hecho, la potencial interposición de representación y uso diferenciado en objetos hispano indígenas de la vida cotidiana pudo ser un referente de la importancia de mantener mecanismos paralelos de reproducción social y afianzamiento identitario. Un manejo de la representación para diferenciar las prácticas afines al sistema colonial de aquellas mantenidas paralelamente, como los encuentros comunales. De alguna forma estaría implicando una resistencia -como la que muestran los documentos para la zona- donde se aíslan dos mundos. La significación puede llegar a ser extensiva a los materiales prehispánicos que sin datos contextuales ni fechados no nos permiten, por ahora, medir con mayor justeza sus trayectorias de uso. De esta situación surgen vacios que nos hacen cuestionar y revisar constantemente nuestras hipótesis y que trataremos de ir rellenando a medida que avancemos en los trabajos de campo y análisis actuales, pero también brotan innumerables y tentadoras preguntas como las que hemos querido dejar planteadas en este trabajo para pensar momentos y situaciones muy complejas de interacción poblacional. Resulta ineludible preguntarse cómo pudieron los objetos reseñados, requeridos por la avidez española o los extirpadores de idolatrías, seguir circulando entre los indígenas durante la Colonia si ese fuere el caso. Sólo mediante prácticas legitimadas ante los españoles o a través de mecanismos que soslayaban el control colonial y factibles si las redes de interacción social se mantenían en funcionamiento. Y los hallazgos en contextos coloniales del delta del Paraná de algunos objetos típicos de las tierras altas, así como de otros comunes a la tradición de la llanura santiagueña o similares a los recuperados en los sitios que nos ocupan apoyarían una visión de las poblaciones de la región capaces de sostener redes de productos, relaciones político sociales, prácticas y significantes materiales durante época Colonial. Todo lo dicho nos permite suponer que en el asentamiento de Sequía Vieja (así como en otros sitios de los alrededores) se mantuvieron durante la Colonia redes y prácticas que esquivaban o resistían el sistema colonial, y que éstas se desarrollaban incluso insertas en uno de los pueblos de indios más importantes de la zona como parece haber sido el que allí se constituyó (Taboada y Farberman 2013). Es claro que varios pueblos de indios se asentaron sobre este sector del Salado y en parte se sobreimpusieron a los asentamientos prehispánicos, y Sequía Vieja parece haber corrido igual suerte. Pero la representación del material colonial (e indígena no local) circulante en el sitio, su aparente sectorización interna, la diferenciación entre los contextos coloniales excavados, el hallazgo de una tapa de pila bautismal finamente decorada, entre otros elementos, nos lleva a pensar que durante la Colonia el asentamiento no sólo se reconfiguró como pueblo de indios sino que mantuvo su preeminencia política en el área, donde convivieron estrategias e intereses tanto españoles como indígenas. Farberman (2002) han señalado que en el Salado las estructuras políticas y los sistemas de autoridad indígena parecen haberse mantenido más tiempo que en la zona del Dulce, y Palomeque (2009) resaltó que fue un área de mayor preservación. Lo que resulta claro también en la continuidad que parece haber mantenido dicha zona en la red de circulación de productos indígenas y en las relaciones intergrupales con poblaciones de otras zonas después de la conquista, como el área del Paraná con las que hemos señalado similitudes materiales de tradición indígena y de prácticas vigentes en momentos coloniales. Más aún, las potenciales evidencias asignables a prácticas de negros esclavos muestra la complejidad de mecanismos que pudieron estar actuando alrededor de este asentamiento. 
Esto cuestiona, en definitiva, algunos estereotipos: como la idea general de un estado de conflicto tanto con las poblaciones de las tierras altas como con los pueblos chaqueños del este del Salado. Y también la concepción que tendió a ver a las sociedades de las llanuras como demasiado simples y receptoras pasivas de influencias. Lo expuesto nos muestra, en cambio, cómo Sequía Vieja pudo ser, entre fines de tiempos prehispánicos y primeros de la Colonia, un eje vertebrador de relaciones pacíficas o negociadas con poblaciones de tierras altas y bajas, incas y chaqueñas, a la vez que desarrollar estrategias para enfrentar la colonización europea.

Agradecimientos: Quiero agradecer a Ana María Lorandi por el acceso a sus registros inéditos sobre Santiago y por la discusión del manuscrito. A Andrés Chazarreta, Director del Museo de Ciencias Antropológicas y Naturales "Emilio y Duncan Wagner" por el permiso para estudiar los materiales. A Patricia Vuoto, Luis Vuoto, Axel Nielsen, Pablo Cruz, Gabriel Coco, Mariano Bonomo, Henrik Lindskoug y Héctor Andreani por las referencias aportadas. A Judith Farberman y Carlos Angiorama por el intercambio de ideas. A los evaluadores por las sugerencias para enriquecer el artículo. A todos los que participaron en los trabajos de campo por su colaboración. A Don Silverio Carrizo, ex ayudante de Emilio Wagner, por mostrarnos el sitio, y a Don Luis Silva y su familia por recibirnos. A Juan Sequeira, intendente de Colonia Dora, por su apoyo. La investigación se encuadra en los proyectos PIP CONICET 11/265 y PICT ANPCyT 1021.

\section{Referencias citadas}

Alconini, S.

2004 The Southeastern Inka frontier against the Chiriguanos: Structure and dynamics of the Inka Imperial borderlands. Latin American Antiquity 15: 389-418.

Angiorama, C. y C. Taboada

2008 Metales andinos en la llanura santiagueña (Argentina). RevistaAndina 47:117-150.

Appadurai, A.

1996 Modernity at Large: Cultural Dimensions of Globalization, University of Minnesota Press, Minneapolis

Bárcena, R.

2001 Estudios sobre el santuario incaico del cerro Aconcagua. En El santuario incaico del cerro Aconcagua (compilado porJ. Schobinger). Universidad Nacional de Cuyo.

Bleiler, E.

1948 The East. NorthwestArgentineArchaeology(ed. por W. Bennett, E. Bleiler y F. Sommer). Yale UniversityPublications in Anthropology 38:120-139. New Haven.

Bonomo, $\mathrm{M}$.

2013Reanálisis de la colección de Samuel Lothrop procedente del delta del Paraná. Relaciones 38 (1):169-198.

Bonomo, M., G. Politis y C. Gianotti

2011 Montículos, jerarquía social y horticultura en las sociedades indígenas del Delta del río Paraná (Argentina). Latin American Antiquity 22:297-333. 
Bourdieu, P.

1988 La Distinción. Taurus, Barcelona.

Carrara, M. y J. De la Penna.

2005. Pipas de fumar africanas en Santa Fe La Vieja. Actas del XIII Congreso Nacional de Arqueología Argentina Tomo 4:155-158. UNC. Córdoba.

Castro, I.

2013La Numeración de los indios del partido del Río Salado. Santiago del Estero, 1607. Encomiendas y servicio personal.Corpus 3 (2):1-16

Castro Rojas, V, y M. Uribe Rodríguez.

2004 Dos "Pirámides" de Caspana. El juego de la Pichica y el dominio Inka en el Loa superior. Chungara (Arica) 36 (suppl.espect2):879-891.

Ceruti, C.

2003 Entidades culturales presentes en lacuenca del Paraná Medio (margen entrerriana). Mundo de Antes, 3:111-135

Combès, I.

2005 Etno-historias del Isoso. Chané y chiriguanos en el Chaco boliviano (siglos XVI a XX). IFEA/ PIEB. La Paz.

Corcuera, R.

2005 Las huellas de al-Andalus. En Teleras. Memorias del Monte Quichua, editado por R. Paz y B. Carballo. Buenos Aires, pp. 173-192. Arte Étnico Argentino.

Cremonte, B. y M. Gheggi

2012 Espacios rituales y cultura material en un sitio arqueológico Humahuaca-Inca (Jujuy, Argentina). Revista Española de Antropología Americana 42(1):9-27.

Cruz P. y R. Jara

2011 Por encima de las nubes. Comechingonia14:75-96.

Cummins, $\mathrm{T}$.

1998 Let me see! Writing is for them. Colonial Andean images and objects: "comoescostumbretener los caciques Senores". En Native Traditions in the Postconquest World, editadopor E. Boone y T. Cummins, pp. 91-148. DumbartonOaks, Washington D.C.

Decoster, J.

2005 Identidad étnica y manipulación cultural: La indumentaria inca en la época colonial. Estudios Atacameños 29:163-170.

Del Río, M.

2010 Los tesoros de los mallkus de Pocona y Totora en el siglo XVI.Chungara 42 (1): 199-220.

Dillehay, $\mathrm{T}$.

2003 El colonialismo inka, el consumo de chicha y los festines desde una perspectiva de banquetes políticos. Boletín de Arqueología PUPCP 7:355-363. Lima. 
Drube, $\mathrm{H}$.

2009 Las poblaciones aborígenes prehispánicas de Santiago del Estero. Evaluación de sus características bioantropológicas y de sus condiciones de salud, enfermedad y nutrición. Tesis doctoral. Universidad Nacional de La Plata, La Plata.

Earle, T.K.

1994 Wealth finance in the Inkaempire: Evidence from the Calchaqui Valley, Argentina. American Antiquity 59:443-460.

Farberman, J.

2002 Feudatarios y tributarios a fines del siglo XVII. La visita de Luján de Vargas a Santiago del Estero (1693). Pervivencia y desestructuración de los pueblos de indios del Tucumán colonial (comp. por J. Farberman y R. Gil Montero.), pp. 59-90. Universidad Nacional de QuilmesUniversidad Nacional de Jujuy, Bernal.

2005 Las salamancas mestizas. De las religiones indígenas a la hechicería colonial. Santiago del Estero, siglo XVIII. Memoria Americana 13: 117-150.

Farberman, J. y C. Taboada

2012 Las sociedades indígenas del territorio santiagueño:apuntes iniciales desde la arqueología y la historia. Runa 33(2):113-132.

Garavaglia, J.

1986 Los textiles de la tierra en el contexto colonial rioplatense: una revolución industrial fallida. Anuario del IEHS 1:45-87.

Gentile, M.

1998La pichca: oráculo y juego de fortuna (su persistencia en el espacio y tiempo andinos). Bulletin de l'Institutfrançaisd'étudesandines 27(1):75-131.

2012 Objetos prehispánicos legados en testamentos de indios (Gobernación de Tucumán, 1608 y 1619). Revista Æquitas 2: 9-43.

González, A. R.

1977 Arte Precolombino en Argentina. Buenos Aires, Filmediciones Valero. 469 pp.

1992 Las placas metálicas de los Andes del Sur. Berlín, KAVA. pp. 311 y láminas.

Gramajo de Martínez Moreno, A.

1979 El Contacto Hispano Indígena en Santiago del Estero con especial referencia a la cerámica. Serie Estudio 2.

1982 Posibles influencias incaicas en Santiago del Estero. Serie Estudio 3:35-59.

1991 Proceso fundacional en el antiguo Tucumán. Ed. V Centenario, 136 págs.

Ibarra Grasso, D. E.

1981 Argentina indígena. Tipográfica Editora Argentina. Buenos Aires.

Leiton, D.

2010 Vasijas como lugares, estilos como paisajes. Tesis de Grado. Universidad Nacional de Tucumán, San Miguel de Tucumán. 
Lemmonier, P.

1992 Elements for an Anthropology of Technology. Anthropological Papers 88. Museum of Anthropology, University of Michigan, Ann Arbor.

Letieri F., G. Cocco, G. Frittegotto, L. Campagnolo, C. Pasquali y C. Giobergia.

S/F Catálogo digital: Santa Fe la Vieja. Bienes arqueológicos del Departamento de Estudios Etnográficos y Coloniales. Ministerio de Innovación y Cultura de la provincia de Santa Fe y el Consejo Federal de Inversiones. Santa Fe. Publicación electrónica: http://www2.ceride.gov. ar/wxis/etnografico/colecciones_arqueologicas/index.htm (consultado el 19/02/2013).

López Campeny, S.

2013 Retomando el hilo... Los torteros arqueológicos de Santiago del Estero. Un giro a la discusión, primeros resultados y propuesta de investigación. Cuadernos del Instituto Nacional de Antropología y Pensamiento Latinoamericano 23.En prensa

Lorandi, A.

S/F Tukuma tukuymanta. Los pueblos del buho. Santiago del Estero antes de la Conquista. En edición. Ms.

1978 El desarrollo cultural prehispánico en Santiago del Estero, Argentina. Journal de la Société des Amèricanistes LXV: 61-85.

1980 La frontera oriental del Tawantinsuyu: El Umasuyu y el Tucumán. Una hipótesis de Trabajo. Relaciones de la Sociedad Argentina de Antropología XIV (1):147-164.

1984 Soñocamayoc. Los Olleros del Inka en los Centros Manufactureros del Tucumán. Revista del Museo de La Plata 8:303-327.

Lorandi, A. y D. Lovera

1972 Economía y patrón de asentamiento en la provincia de Santiago del Estero. Relaciones de la Sociedad Argentina de Antropología VI:173-191.

Lucaioli, C.

2005 Los Grupos Abipones hacia Mediados del Siglo XVIII. Sociedad Argentina de Antropología. Buenos Aires.

Mayer, E.

1986 Vorspanische Metallwaffen und-wekzeuge in Argentinien und Chile. Armas y herramientas de metal prehispánicas en Argentina y Chile. München, Verlag C. H. Beck.

McCormac, F.; A. Hogg; P. Blackwell; C. Buck; T. Higham y P. Reimer.

2004 SHCal04 Southern Hemisphere Calibration 0-1000 cal BP. Radiocarbon 46, 1087-1092.

Métraux, A.

1929Etudes sur la civilisation des indiens chiriguano. Revista del Instituto de Etnología 1:295480. Universidad Nacional de Tucumán.

Nielsen, A.

2006 Pobres jefes. Aspectos corporativos en las formaciones sociales pre-inkaicas de los Andes circunpuneños. En: Contra la tiranía tipológica en Arqueología (editado por C. Gnecco y C. Langebaek). Uniandes - Ceso. pp. 121-150. 
Oliveto, G. y B. Ventura

2009 Dinámicas poblacionales de los Valles Orientales del sur de Bolivia y norte de Argentina, siglos XV-XVII. Población y Sociedad 16: 119-150.

Palomeque, S.

2009 El Tucumán durante los siglos XVI y XVII. La destrucción de las ‘Tierras Bajas' en aras de la conquista de las 'Tierras Altas'. En Las Sociedades de los paisajes áridos y semiáridos del centro oeste argentino (compilado por Martini, Pérez Zavala y Aguilar). Universidad Nacional de Río Cuarto. pp. 173-206.

Paucke, F.

1943 Hacia Allá y para Acá. Una Estadía entre los Indios Mocobíes, 1749-1767. Universidad Nacional de Tucumán, San Miguel de Tucumán.

Pärssinen M. y Siriäinen

2003 Andes Orientales y Amazonia Occidental. Ensayos entre la Historia y la Arqueología de Bolivia, Brasil y Perú.Colegio Nacional de Historiadores de Bolivia y CIMA. La Paz.

Pedersen, A.

1952 Objetos de bronce de la zona del Río Salado (región Chaco-Santiagueña). Proceedings of the XXX International Congress of Americanistes, pp. 92-100.

Politis, G. y M. Bonomo.

2012 La entidad arqueológica Goya-Malabrigo (ríos Paraná y Uruguay) y su filiación arawak. Revista de Arqueologia,Sociedade de Arqueologia Brasileira 25(1): 10-46.

Reichlen, $\mathrm{H}$.

1940 Recherches Archéologiques dans la Province de Santiago del Estero (Rép. Argentine). Journal de la Societé des Amèricanistes LXV:133-225.

Salomon, F.

2002 «Huayrahuayrapichcamanta!»: augurio, risa, y regeneración en la política tradicional. Bulletin de l'InstitutFrançaisd'ÉtudesAndines 31(1):1-22.

Serrano, A.

1938 La Etnografía Antigua de Santiago del Estero y la llamada Civilización Chaco-Santiagueña. Editores Casa Predassi, Paraná.

Taboada, C.

2011 Repensando la Arqueología de Santiago del Estero. Construcción y análisis de una problemática. Relaciones de la Sociedad Argentina de Antropología XXXVI: 197-220.

2013a Espacio, cultura material y procesos sociales en la llanura santiagueña. En: Arqueología y Etnohistoria de la Vertiente Oriental de los Andes. UNJU.

2013b Sequía Vieja: ¿un sitio de encuentro interétnico en la llanura santiagueña? Libro de Resumenes del XVIII Congreso Nacional de Arqueología Argentina. Universidad Nacional de La Rioja, La Rioja. 
Taboada, C. y C. Angiorama

2005 Informe Final de las tareas de prospección realizadas en Santiago del Estero. Informe inédito Presentado al Museo de Ciencias Antropológicas y Naturales "Emilio y Duncan Wagner", Santiago del Estero.

2010 Metales, textiles y cerámica. Tres líneas de análisis para pensar una vinculación entre los habitantes de la llanura santiagueña y el Tawantinsuyu. Memoria Americana 18 (2):11- 41. Taboada, C., C. Angiorama, D. Leiton y S. M. L. López Campeny

2013 En la llanura y los valles... Relaciones entre poblaciones de las tierras bajas santiagueñas y el estado inca: materialidades, elecciones y repercusiones. Intersecciones en Antropología.. 14: 137-156.

Taboada C. y J. Farberman

2013 Arqueología e historia en Santiago del Estero. Desarrollos locales e interacción entre el período tardío y la colonia temprana. Ponencia presentada a las XIV Jornadas Interescuelas/ Deptos. de Historia. UNCuyo. Mendoza

Wagner, E. y O. Righetti

1946 Archéologie Comparée. Résume de Préhistoire. Buenos Aires.

Wagner, E. y D. Wagner

1934 La Civilización Chaco-Santiagueña y sus correlaciones con las del Viejo y Nuevo Mundo. Tomo I. Compañía Impresora Argentina S. A. Buenos Aires. 